\title{
PENGARUH ZPT TERHADAP PERTUMBUHAN DAN PRODUKSI BEBERAPA VARIETAS JAGUNG MANIS (Zea mays L.) DI LAHAN SALIN
}

\author{
Rima Rizka Arozza Matondang \\ Program Studi Agroteknologi \\ Fakultas Pertanian, Universitas Sumatera Utara, Medan 20155, Indonesia \\ rimarizka@gmail.com
}

\begin{abstract}
This study aims to determine the effect of zpt on the growth and production of some sweet corn varieties in the saline field. This research was conducted in May until July 2017. The research used factorial randomized block design with 15 treatments and 4 replications. The parameters observed were plant length, number of leaves, flowering age of male and female, length of cob, number of cobs of crop, weights of cob and weight of 100 seeds per plot. The results showed that the observation of varieties treatment was significantly different to the height of tanama (cm) and weight of 100 seeds (gram). Observation of the treatment of ZPT Atonik and Novelgro Alpha was significantly different to the parameters of plant height (cm), number of leaves (strands), harvest age, cob length ( $\mathrm{cm}$ ) and cob weight (gram). The observation of interaction treatment between varieties and ZPT Atonik and Novelgro Alpha had significant effect on plant height (cm), number of leaves (strands), number of cobs, gram length and gram weights.
\end{abstract}

\begin{abstract}
Abstrak
Penelitian ini bertujuan untuk mengetahui pengaruh zpt terhadap pertumbuhan dan produksi beberapa varietas jagung manis di lahan salin. Penelitian ini dilakukan pada bulan Mei-Juli 2017 menggunakan rancangan acak kelompok faktorial dengan 15 perlakuan dan 4 ulangan yaitu faktor I V1 (Jagung Varietas Bonanza), V2 (Jagung Varietas Secada), V3 (Jagung Varietas Pioneer 32) dan faktor II H0 (Kontrol), H1 (Novelgro Alpha 2 m/l), H2 (Novelgro Alpha 4 m/l), H3 (Atonik 2 m/l), H4 (Atonik 4 m/l). Parameter yang diamati adalah panjang tanaman, jumlah daun, umur berbunga jantan dan betina, panjang tongkol, jumlah tongkol pertanaman, bobot tongkol dan bobot 100 biji per plot. Hasil penelitian menunjukkan bahwa pengamatan perlakuan varietas berbeda nyata terhadap parameter tinggi tanama $(\mathrm{cm})$ dan bobot 100 biji (gram). Pengamatan perlakuan ZPT Atonik dan Novelgro Alpha berbeda nyata terhadap parameter tinggi tanaman $(\mathrm{cm})$, jumlah daun (helai), umur panen, panjang tongkol $(\mathrm{cm})$ dan bobot tongkol (gram). Pengamatan perlakuan interaksi antar varietas dan ZPT Atonik dan Novelgro Alpha berpengaruh nyata terhadap parameter tinggi tanaman (cm), jumlah daun (helai), jumlah tongkol (buah), panjang tongkol (gram) dan bobot tongkol (gram).
\end{abstract}

Kata Kunci : Jagung, ZPT Novelgro Alpha dan Atonik Salin.

\section{Pendahuluan}

Banyak jenis jagung manis yang dibudidayakan untuk pangan oleh petani diantaranya adalah jagung mutiara. Jagung ini banyak dibudidayakan di Indonesia karena keunggulannya tahan 
terhadap hama digudang pada saat penyimpanan. Jagung manis (sweet corn) juga banyak dibudidayakan di Indonesia khususnya karena rasa manis dan banyak dijadikan jajanan pasar aneka rasa seperti bahan syrup dan ice cream yang semakin banyak peminatnya. Jagung ketan atau pulut lebih populer digunakan sebagai campuran makanan karena seluruh kandungan pati jagung ini mengandung $100 \%$ amilopektine. Ada juga jagung brondong (pop corn) yang banyak dijadikan cemilan atau jajanan ringan atau lebih umum dikenal dengan Popcorn ( Sirait, 2016).

Tanah salin dapat mempengaruhi beberapa proses fisiologi dari mulai perkecambahan sampai pertumbuhan tanaman. Kandungan $\mathrm{NaCl}$ yang tinggi pada tanah salin menyebabkan rusaknya struktur tanah, sehingga aerasi dan permeabilitas tanah menyebabkan berkurangnya ion-ion $\mathrm{Ca}, \mathrm{Mg}$ dan $\mathrm{K}$ yang dapat ditukar, yang berarti menurunnya ketersediaan unsur hara tersebut bagi tanaman. Bertambahnya konsentrasi garam didalam suatu larutan tanah, meningkatkan potensial osmotik larutan tanah tersebut. Oleh karena itu, salinitas dapat menyebabkan tanaman sulit menyerap air hingga terjadi kekeringan fisiologis. Maka untuk mengatasi kekurangan unsur hara tersebut digunakanlah zat pengatur tumbuh (ZPT) atonik dan novelgro alpha sebagai unsur hara penunjang untuk melihat pengaruhnya (Lovadi, et.al, 2015).

Pada tanaman jagung manis dengan pemberian atonik konsentrasi yang pernah dipakai sebesar $0,5 \mathrm{ml} / \mathrm{l}$ dan novelgro sebesar $1 \mathrm{ml} / 1$. Cara pengaplikasian yang dilakukan adalah dengan perlakuan perendaman benih dalam larutan atonik dan novelgro dilakukan selama 24 jam sebelum ditanam dengan konsentrasi 1 : 1000 (Sembiring, 2008).

Zat pengatur tumbuh merupakan senyawa organik lengkap, selain dari nutrisi, yang memodifikasi proses fisiologi tanaman. ZPT disebut biostimulan atau penghambat alami, yang bertindak di dalam sel-sel tanaman untuk menstimulasi atau menghambat enzim tertentu atau enzim sistem dan membantu mengatur metabolisme tanaman. Mereka biasanya aktif pada konsentrasi yang sangat rendah pada tanaman (Harms dan Oplinger, 1988).

Atonik termasuk dalam kelompok auksin yang mengandung bahan aktif natrium otrhonitrofenol, natrium para-nitrofenol, natrium 2-4 dinitrofenol, dan natrium 5 nitroguaiakol. Senyawa tersebut sangat efektif dalam mengatur pertumbuhan akar, meningkatkan keberhasilan perakaran stek, mempercepat perakaran, dan meningkatkan kualitas akar adventif. Proses munculnya akar adventif terdiri dari tiga tahap yaitu: 1 . Terjadi diferensiasi sel yang diikuti dengan terbentuknya sel-sel meristematis (inisiasi akar), 2. Diferensiasi selsel meristematis hingga terbentuknya primordia akar, dan 3. mulai munculnya akar-akar baru (Ashari, 1995 dalam Dharma et al., 2011).

Novelgro Alpha adalah zat pengatur tumbuh tanaman yang diperoleh dari ekstraksi sel primordia tanaman yang mengandung sitokinin. Sitokinin berfungsi untuk merangsang pembelahan sel, dalam hal ini pembelahan sel (sitokinesis) bekerja pada butir klorofil. Butir 
klorofil merupakan pabrik fotosintesis yang bertugas mengubah energi kinetik dan atahari menjadi energi potensial berupa karbohidrat bagi tanaman. Meningkatnya jumlah butir klorofil akan meningkatkan efektivitas fotosintesis yang akhirnya meningkatkan hasil produksi tanaman (Sardian, 2009).

\section{Bahan dan Metode}

Penelitian ini dilakukan di Desa Terjun Kecamatan Hamparan Perak Kabupaten Deli Serdang Sumatera Utara, Medan dengan ketinggian tempat $+18 \mathrm{~m}$ dpl. Penelitian ini dilaksanakan pada bulan Mei 2017 sampai dengan selesai.

Bahan yang digunakan pada penelitian ini adalah benih jagung varietas Bonanza, Secada dan Pioneer 32 sebagai varietas yang digunakan, pupuk Urea, SP 36 dan KCL sebagai pupuk dasar, Atonik dan Novelgro Alpha sebagai fitohormon, air untuk menyiram, dan label untuk memberi tanda, Polibang sebagai media tanam.

Alat yang digunakan pada penelitian ini adalah meteran untuk mengukur lahan yang digunakan, timbangan untuk menimbang jagung yang dipanen, gembor alat menyiram tanaman, kamera untuk media dokumentasi, cangkul untuk membuatan lahan.

Penelitian ini menggunakan Rancangan Acak Kelompok (RAK) 2 faktor. Faktor pertama adalah varietas (V) dan faktor kedua adalah konsentrasi Atonik dan Novelgro Alpha (H).Data dianalisis dengan ANOVA, kemudian dilanjutkan ke uji Duncan'sMultiple Range Test (DMRT) pada taraf 5\%.

Parameter yang di amati antara lain : Panjang Tanaman (cm), Jumlah daun (Helai), Umur berbunga (HST), Umur panen (HST), Panjang tongkol (cm), Jumlah tongkol per tanaman (buah) dan Bobot tongkol (g).

\section{Hasil dan Pembahasan}

Hasil

Dari penelitian yang telah dilaksanakan diperoleh bahwa genotip berbeda nyata terhadap karakter tinggi tanaman $(\mathrm{cm})$ dan bobot 100 biji $(\mathrm{g})$, tetapi tidak berbeda nyata pada karakter jumlah daun (helai), umur berbunga jantan dan betina, umur panen, jumlah tongkol (buah), panjang tongkol $(\mathrm{cm})$ dan bobot tongkol $(\mathrm{g})$. Pemberian ZPT berpengaruh nyata pada karakter tinggi tanaman $(\mathrm{cm})$, jumlah daun (helai), umur panen, panjang tongkol $(\mathrm{cm})$ dan bobot tongkol $(\mathrm{g})$, tetapi tidak berpengaruh nyata pada karakter umur berbunga jantan dan betina, jumlah tongkol (buah) dan bobot 100 biji. Interaksi genotip x pemberian ZPT berpengaruh nyata pada karakter tinggi tanaman $(\mathrm{cm})$, jumlah daun (helai), jumlah tongkol (buah), panjang tongkol $(\mathrm{cm})$ dan bobot tongkol(g). 
Tabel 1. Hasil Analisis Ragam Gabungan Beberapa Varietas Jagung Terhadap Pemberian ZPT

\begin{tabular}{rlccc}
\hline No. & \multicolumn{1}{c}{ Karakter } & $\begin{array}{c}\text { KT } \\
\text { Genotipe }\end{array}$ & $\begin{array}{c}\text { KT Pemberian } \\
\text { ZPT }\end{array}$ & $\begin{array}{c}\text { KT Genotipe } \mathbf{x} \\
\text { Pemberian ZPT }\end{array}$ \\
\hline 1 & Tinggi Tanaman $(\mathrm{cm})$ & $33348.92^{*}$ & $322.29^{*}$ & $519.40^{*}$ \\
2 & Jumlah Daun (Helai) & $1.55 \mathrm{tn}$ & $2.31 *$ & $1.90 *$ \\
3 & Umur Bunga Jantan & $0.46 \mathrm{tn}$ & $0.14 \mathrm{tn}$ & $0.09 \mathrm{tn}$ \\
4 & Umur Bunga Betina & $0.46 \mathrm{tn}$ & $0.47 \mathrm{tn}$ & $0.11 \mathrm{tn}$ \\
5 & Umur Panen & $0.20 \mathrm{tn}$ & $4.40^{*}$ & $1.20 \mathrm{tn}$ \\
6 & Jumlah Tongkol (Buah) & $0.09 \mathrm{tn}$ & $0.01 \mathrm{tn}$ & $0.06 *$ \\
7 & Panjang Tongkol $(\mathrm{cm})$ & $26.82 \mathrm{tn}$ & $53.01 *$ & $50.15 *$ \\
8 & Bobot Tongkol $(\mathrm{g})$ & $1011.60 \mathrm{tn}$ & $2496.00 *$ & $1708.63 *$ \\
9 & Bobot 100 Biji $(\mathrm{g})$ & $19.37 *$ & $4.07 \mathrm{tn}$ & $9.79 \mathrm{tn}$ \\
\hline
\end{tabular}

Keterangan : $*$ berpengaruh nyata pada taraf $0.05, \mathrm{tn}=$ tidak nyata

Hasil analisis statistik menunjukkan bahwa analisis ragam gabungan berpengaruh nyata pada karakter tinggi tanaman $(\mathrm{cm})$ dan bobot 100 biji (gr), dan pada karakter lainnya tidak berpengaruh nyata. Faktor pemberian ZPT berpengaruh nyata pada variabel pengamatan tinggi tanaman $(\mathrm{cm})$, jumlah daun (helai), umur panen, panjang tongkol $(\mathrm{cm})$, dan bobot tongkol (gr). Sedangkan interaksi antar genotipe dan pemberian ZPT berpengaruh nyata pada variabel pengamatan tinggi tanaman $(\mathrm{cm})$, jumlah daun (helai), jumlah tongkol (buah), panjang tongkol $(\mathrm{g})$, dan bobot tongkol $(\mathrm{g})$.

Tabel 2. menunjukkan bahwa rataan tertinggi varietas Bonanza F1 pada karakter tinggi tanaman yaitu $140.12 \mathrm{~cm}$ dan rataan terendah adalah karakter jumlah tongkol yaitu 1.65 buah. Rataan tertinggi untuk varietas Secada adalah karakter bobot tongkol yaitu 93.70 gram dan rataan terendah adalah karakter jumlah tongkol yaitu 1.03 buah.

Tabel 2. Data Rataan Varietas Tanaman Jagung (Zea mays L.)

\begin{tabular}{clccc}
\hline No & Variabel Amatan & Bonanza F1 & $\begin{array}{c}\text { Varietas } \\
\text { Secada }\end{array}$ & Pioner 32 \\
\hline 1 & Tinggi Tanaman (cm) & $140.12 \mathrm{~b}$ & $78.97 \mathrm{c}$ & $156.42 \mathrm{a}$ \\
2 & Jumlah Daun (helai) & $9.25 \mathrm{ab}$ & $9.05 \mathrm{~b}$ & $9.60 \mathrm{a}$ \\
3 & Umur Bunga Jantan & $52.70 \mathrm{a}$ & $52.60 \mathrm{a}$ & $52.40 \mathrm{a}$ \\
4 & Umur Bunga Betina & $62.70 \mathrm{a}$ & $62.40 \mathrm{a}$ & $62.60 \mathrm{a}$ \\
5 & Umur Panen & $87.80 \mathrm{a}$ & $87.70 \mathrm{a}$ & $87.90 \mathrm{a}$ \\
6 & Jumlah Tongkol (buah) & $1.65 \mathrm{ab}$ & $1.03 \mathrm{~b}$ & $1.15 \mathrm{a}$ \\
7 & Panjang Tongkol (cm) & $17.15 \mathrm{a}$ & $17.02 \mathrm{a}$ & $19.08 \mathrm{a}$ \\
8 & Bobot Tongkol (gram) & $91.78 \mathrm{a}$ & $93.70 \mathrm{a}$ & $104.94 \mathrm{a}$ \\
9 & Bobot 100 Biji (gram) & $14.84 \mathrm{a}$ & $13.12 \mathrm{~b}$ & $14.81 \mathrm{a}$ \\
\hline
\end{tabular}

Keterangan : Angka yang diikuti oleh huruf yang sama, berbeda tidak nyata pada $\alpha=0.05$ dengan uji Duncan

Perbedaan respon pertambahan tinggi tanaman menunjukkan bahwa pengaruh genetik tiap varietas berbeda pada setiap fase pertumbuhan dan tiap varietas juga memiliki susunan genetik yang berbeda meskipun ketiga varietas tersebut merupakan jenis tanaman yang sama. 
Tabel 3 menunjukkan bahwa pada karakter tinggi tanaman $(\mathrm{cm})$ rataan tertinggi terdapat pada perlakuan kontrol (H0) yaitu $131.45 \mathrm{~cm}$, perlakuan Novelgro Alpha $4 \mathrm{ml}(\mathrm{H} 2)$ yaitu $127,31 \mathrm{~cm}$. Sedangkan data rataan terendah terdapat pada $\mathrm{H} 4$ yaitu perlakuan Atonik $4 \mathrm{ml}$ yaitu 117,62 cm dan berbeda nyata pada perlakuan lainnya. Perlakuan Novelgro $4 \mathrm{ml}(\mathrm{H} 2)$ dan Atonik $2 \mathrm{ml}(\mathrm{H} 3)$ tidak berbeda nyata pada variabel pengamatan tinggi tanaman.

Tabel 3. Data Rataan ZPT (Zat Pengatur Tumbuh) Tanaman Jagung (Zea mays L.)

\begin{tabular}{clccccc}
\hline \multirow{2}{*}{ No } & \multirow{2}{*}{ Variabel Amatan } & \multicolumn{5}{c}{ ZPT (Zat Pengatur Tumbuh) } \\
& & H0 & H1 & H2 & H3 & H4 \\
\hline 1 & Tinggi Tanaman $(\mathrm{cm})$ & $131.45 \mathrm{a}$ & $123.01 \mathrm{bc}$ & $127.31 \mathrm{ab}$ & $126.47 \mathrm{ab}$ & $117.62 \mathrm{c}$ \\
2 & Jumlah Daun (helai) & $8.92 \mathrm{bc}$ & $9.50 \mathrm{ab}$ & $9.58 \mathrm{a}$ & $9.75 \mathrm{a}$ & $8.75 \mathrm{a}$ \\
3 & Umur Bunga Jantan & $52.66 \mathrm{a}$ & $52.50 \mathrm{a}$ & $52.66 \mathrm{a}$ & $52.58 \mathrm{a}$ & $52.42 \mathrm{a}$ \\
4 & Umur Bunga Betina & $62.25 \mathrm{~b}$ & $62.50 \mathrm{ab}$ & $62.75 \mathrm{a}$ & $62.66 \mathrm{ab}$ & $62.66 \mathrm{ab}$ \\
5 & Umur Panen & $88.50 \mathrm{a}$ & $87.16 \mathrm{~b}$ & $87.16 \mathrm{~b}$ & $88.00 \mathrm{a}$ & $88.16 \mathrm{a}$ \\
6 & Jumlah Tongkol & $1.04 \mathrm{a}$ & $1.04 \mathrm{a}$ & $1.08 \mathrm{a}$ & $1.08 \mathrm{a}$ & $1.12 \mathrm{a}$ \\
7 & Panjang Tongkol (cm) & $14.06 \mathrm{~b}$ & $18.85 \mathrm{a}$ & $19.25 \mathrm{a}$ & $18.15 \mathrm{a}$ & $18.43 \mathrm{a}$ \\
8 & Bobot Tongkol (gram) & $71.08 \mathrm{~b}$ & $102.33 \mathrm{a}$ & $105.11 \mathrm{a}$ & $102.67 \mathrm{a}$ & $102.85 \mathrm{a}$ \\
9 & Bobot 100 Biji (gram) & $13.41 \mathrm{a}$ & $14.59 \mathrm{a}$ & $14.83 \mathrm{a}$ & $13.92 \mathrm{a}$ & $14.54 \mathrm{a}$ \\
\hline \multicolumn{7}{c}{ Keterangan : Angka yang diikuti oleh huruf yang sama, berbeda tidak nyata pada } \\
\multicolumn{7}{c}{$\alpha=0.05$ dengan uji Duncan }
\end{tabular}

Tabel 4 menunjukkan bahwa data rataan tertinggi pada karakter tinggi tanaman $(\mathrm{cm})$ adalah varietas Secada (V2) yaitu Atonik $2 \mathrm{ml} 175.61 \mathrm{~cm}$ dan berbeda nyata dengan varietas Bonanza F1 (V1) dan varietas Secada (V2). Rataan terendah terdapat pada varietas Pioner 32 (V3) yaitu Novelgro Alpa $2 \mathrm{ml} 75.09 \mathrm{~cm}$ dan berbeda nyata dengan varietas Bonanza F1 (V1) dan varietas Secada (V2).

Tabel 4. Data Interaksi Variabel Tinggi Tanaman (cm)

\begin{tabular}{lcccccc}
\hline Varietas & \multicolumn{5}{c}{ Tinggi Tanaman 7 MST (cm) } & Rataan \\
& $\mathrm{H} 0$ & $\mathrm{H} 1$ & $\mathrm{H} 2$ & $\mathrm{H} 3$ & $\mathrm{H} 4$ & $(\mathrm{~cm})$ \\
\hline V1 & $143.66 \mathrm{cde}$ & $140.00 \mathrm{~h}$ & $83.41 \mathrm{def}$ & $78.31 \mathrm{def}$ & $160.63 \mathrm{~cd}$ & $121.20 \mathrm{~b}$ \\
V2 & $130.99 \mathrm{~h}$ & $145.76 \mathrm{gh}$ & $81.10 \mathrm{~h}$ & $175.61 \mathrm{~h}$ & $162.48 \mathrm{~h}$ & $139.19 \mathrm{c}$ \\
V3 & $140.21 \mathrm{a}$ & $75.09 \mathrm{bc}$ & $76.95 \mathrm{ab}$ & $154.64 \mathrm{ab}$ & $128.79 \mathrm{fg}$ & $115.14 \mathrm{a}$ \\
\hline Rataan & 138.29 & 120.28 & 80.49 & 136.19 & 150.63 & \\
\hline
\end{tabular}

Keterangan : Angka yang diikuti oleh huruf yang sama, berbeda tidak nyata pada $\alpha=0.05$ dengan uji Duncan 
Tabel 5. Data Interaksi Variabel Jumlah Daun (helai)

\begin{tabular}{lcccccc}
\hline Varietas & \multicolumn{5}{c}{ Jumlah Daun 7 MST (cm) } & Rataan \\
& $\mathrm{H} 0$ & $\mathrm{H} 1$ & $\mathrm{H} 2$ & $\mathrm{H} 3$ & $\mathrm{H} 4$ & $(\mathrm{~cm})$ \\
\hline V1 & $9.25 \mathrm{ab}$ & $9.75 \mathrm{ab}$ & $9.75 \mathrm{ab}$ & $7.25 \mathrm{ab}$ & $10.00 \mathrm{ab}$ & 9.2 \\
V2 & $9.00 \mathrm{~b}$ & $9.25 \mathrm{ab}$ & $9.75 \mathrm{ab}$ & $8.75 \mathrm{ab}$ & $9.75 \mathrm{c}$ & 9.3 \\
V3 & $9.00 \mathrm{~b}$ & $8.75 \mathrm{ab}$ & $9.75 \mathrm{ab}$ & $9.75 \mathrm{ab}$ & $9.75 \mathrm{ab}$ & 9.4 \\
\hline Rataan & 0.08 & 9.25 & 9.75 & 8.58 & 9.83 &
\end{tabular}

Keterangan : Angka yang diikuti oleh huruf yang sama, berbeda tidak nyata pada $\alpha=0.05$ dengan uji Duncan

Pada karakter umur berbungan jantan, jumlah tongkol, dan bobot 100 biji tidak berbeda nyata antar perlakuan ZPT (zat pengatur tumbuh). Sedangkan pada perlakuan jumlah daun perlakuan kontrol berbeda nyata dengan perlakuan lainnya.

Tabel 6. Data Interaksi Variabel Jumlah Tongkol (buah)

$$
\text { Jumlah Tongkol (buah) }
$$

\begin{tabular}{|c|c|c|c|c|c|c|}
\hline Varietas & $\mathrm{H} 0$ & $\mathrm{H} 1$ & $\mathrm{H} 2$ & $\mathrm{H} 3$ & $\mathrm{H} 4$ & $\begin{array}{c}\text { Rataan } \\
(\mathrm{cm})\end{array}$ \\
\hline V1 & $1.13 \mathrm{ab}$ & $1.13 \mathrm{~b}$ & $1.00 \mathrm{~b}$ & $1.00 \mathrm{ab}$ & $1.25 \mathrm{~b}$ & 1.10 \\
\hline V2 & $1.00 \mathrm{~b}$ & $1.00 \mathrm{~b}$ & $1.00 \mathrm{~b}$ & $1.00 \mathrm{~b}$ & $1.00 \mathrm{~b}$ & 1.00 \\
\hline V3 & $1.00 \mathrm{~b}$ & $1.00 \mathrm{ab}$ & $1.13 \mathrm{ab}$ & $1.13 \mathrm{~b}$ & $1.38 \mathrm{a}$ & 1.13 \\
\hline Rataan & 1.04 & 1.04 & 1.04 & 1.04 & 1.21 & \\
\hline
\end{tabular}

Interaksi antar perlakuan varietas dan ZPT pada karakter jumlah tongkol (buah) berpengaruh nyata. Rataan tertinggi pada varietas Pioner 32 (V3) dan tidak berbeda nyata dengan varietas Bonanza F1 (V1) dan Secada (V2). Rataan terendah adalah varietas Secada (V2) dan tidak berbeda nyata dengan varietas Bonanza F1 (V1) dan Pioner 32 (V3). Perlakuan ZPT (zat pengatur tumbuh) juga tidak berpengaruh nyata antar perlakuan masing-masing.

Tabel 7. Data Interaksi Variabel Panjang Tongkol $(\mathrm{cm})$

\begin{tabular}{llccccc}
\hline \multirow{2}{*}{ Varietas } & \multicolumn{7}{c}{ Panjang Tongkol $(\mathrm{cm})$} \\
& $\mathrm{H} 0$ & $\mathrm{H} 1$ & $\mathrm{H} 2$ & $\mathrm{H} 3$ & $\mathrm{H} 4$ & Rataan $(\mathrm{cm})$ \\
\hline V1 & $18.90 \mathrm{abcd}$ & 17.59 abcde & $18.29 \mathrm{bcde}$ & $16.76 \mathrm{bcde}$ & $21.39 \mathrm{cde}$ & 18.59 \\
V2 & $18.38 \mathrm{e}$ & $13.78 \mathrm{abcde}$ & $19.28 \mathrm{abcd}$ & $12.05 \mathrm{abc}$ & $17.34 \mathrm{bcde}$ & 16.16 \\
V3 & $17.10 \mathrm{de}$ & $11.25 \mathrm{abc}$ & $19.54 \mathrm{ab}$ & $19.89 \mathrm{bcde}$ & $24.78 \mathrm{a}$ & 18.51 \\
\hline Rataan & 18.1 & 14.21 & 19.03 & 16.23 & 21.17 & \\
\hline \multicolumn{7}{c}{ Keterangan : Angka yang diikuti oleh huruf yang sama, berbeda tidak nyata pada } \\
$\alpha=0.05$ dengan uji Duncan
\end{tabular}


Interaksi antar perlakuan varietas dan ZPT pada karakter panjang tongkol $(\mathrm{cm})$ berpengaruh nyata. Rataan tertinggi adalah varietas Bonanza F1 (V1) dan tidak berbeda nyata dengan varietas Secada (V2) dan Pioner 32 (V3). Rataan terendah adalah varietas Secada (V2) dan tidak berbeda nyata dengan varietas varietas Bonanza F1 (V1) dan Pioner 32 (V3). Perlakuan ZPT (zat pengatur tumbuh) juga tidak berpengaruh nyata antar perlakuan masing-masing.

Tabel 8. Data Interaksi Variabel Bobot Tongkol (g)

\begin{tabular}{lcccccc}
\hline \multirow{2}{*}{ Varietas } & \multicolumn{7}{c}{ Bobot Tongkol (gr) } \\
& $\mathrm{H} 0$ & $\mathrm{H} 1$ & $\mathrm{H} 2$ & $\mathrm{H} 3$ & $\mathrm{H} 4$ & $\begin{array}{c}\text { Rataan } \\
(\mathrm{cm})\end{array}$ \\
\hline V1 & $98.44 \mathrm{bc}$ & $90.79 \mathrm{bc}$ & $97.45 \mathrm{bc}$ & $89.75 \mathrm{bc}$ & $111.61 \mathrm{bc}$ & $97.61 \mathrm{~b}$ \\
V2 & $98.48 \mathrm{c}$ & $77.97 \mathrm{bc}$ & $110.49 \mathrm{~b}$ & $55.90 \mathrm{ab}$ & $105.31 \mathrm{bc}$ & $89.63 \mathrm{c}$ \\
V3 & $93.23 \mathrm{c}$ & $58.23 \mathrm{c}$ & $111.92 \mathrm{ab}$ & $111.06 \mathrm{ab}$ & $140.86 \mathrm{ab}$ & $103.20 \mathrm{a}$ \\
\hline Rataan & 96.7 & 75.89 & 106.62 & 85.57 & 119.26 & \\
\hline
\end{tabular}

Keterangan : Angka yang diikuti oleh huruf yang sama, berbeda tidak nyata pada $\alpha=0.05$ dengan uji Duncan

Interaksi antar perlakuan varietas dan ZPT pada karakter bobot tongkol (gr) berpengaruh nyata. Rataan tertinggi adalah varietas Pioner 32 (V3) dan berbeda nyata dengan varietas Bonanza F1 (V1) dan Secada (V2). Rataan terendah adalah varietas Secada (V1) dan berbeda nyata dengan varietas Bonanza F1 (V1) dan Pioner 32 (V3). Perlakuan ZPT (zat pengatur tumbuh) juga tidak berpengaruh nyata antar perlakuan masing-masing.

\section{Simpulan}

Perlakuan varietas berbeda nyata terhadap parameter tinggi tanaman $(\mathrm{cm})$ dan bobot 100 biji (g). Perlakuan ZPT Atonik dan Novelgro Alpha berbeda nyata terhadap parameter tinggi tanaman $(\mathrm{cm})$, jumlah daun (helai), umur panen, panjang tongkol $(\mathrm{cm})$ dan bobot tongkol (g). Ini menyatakan bahwa ZPT Atonik dan Novelgro Alpha memberikan efek merangsang pertumbuhan untuk jagung. Perlakuan interaksi antar varietas dan ZPT Atonik dan Novelgro Alpha berpengaruh nyata terhadap parameter tinggi tanaman $(\mathrm{cm})$, jumlah daun (helai), jumlah tongkol (buah), panjang tongkol (g) dan bobot tongkol (g).

\section{Referensi}

Ashari, S. 1995. Hortikultura Aspek Budidaya. dalam Darma, D. P., I M. Ardaka, I G. Tirta. 2011. Pengaruh Jumlah Ruas dan Zat Pengatur Tumbuh Terhadap Pertumbuhan Stek Pranajiwa (Euchresta horsfieldii (Lesch.) Benth. Jurnal Penelitian Hutan Tanaman Vol. 8 No. 2, April 2011.

Harms, C. L. And E. S. Oplinger. 1988. Plant Growth Regulators: Their Use In Crop Production. North Central Region Extension Publication 303. Diakses melalui: http://www.extension.umn.edu (26 Februari 2015).

Lovadi, I. Eti, D.A. dan Mukarlina. 2015. Toleransi Tanaman Sawi Hijau (Brassica juncea L.) Terhadap Cekaman Salinitas Garam NaCl. Fakultas Biologi. Universitas Tanjungpura. Pontianak. 
Sardian, L. 2009. Uji Coba Novelgro Terra Pada Tanaman Jagung di Indonesia. Universitas Lampung. Lampung

Sembiring, B. 2008. Zat Pengatur Tumbuh. Jakarta.

Pertumbuhan Karakter Vegetatif Awal Beberapa Genotipe Sorgum ( Sorghum bicolor L. Moench) Terhadap Toksisitas Aluminium Pada Media Kultur Hara. Fakultas Pertanian. Universitas Andalas. Padang. 